\title{
Alkyl Phosphate Functionalized Gold Nanoparticles-Based Colorimetric Probe for $\mathrm{Pb}^{2+}$ ions
}

\author{
Seung Kyung Kim, Sudeok Kim, Eun Ji Hong, and Min Su Han* \\ Department of Chemistry, Chung-Ang University, Seoul 156-756, Korea.*E-mail: mshan@cau.ac.kr \\ Received September 14, 2010, Accepted October 13, 2010
}

Key Words: Colorimetric, $\mathrm{Pb}^{2+}$, Gold nanoparticle, Probe

Lead is a common pollutant that is released routinely from a range of sources, such as lead-acid batteries, lead wire or pipes, paint, and metal recycling and foundries. Lead is extremely toxic to many organs and tissues, and interferes with a variety of vital processes. ${ }^{1}$ In particular, the lead interferes with the development of the nervous system, which can cause learning and behavior disorders in children. ${ }^{2}$ The detection of $\mathrm{Pb}^{2+}$ has attracted considerable attention in recent years and many optical probes for $\mathrm{Pb}^{2+}$ have been developed using organic dyes. ${ }^{3} \mathrm{Al}$ though colorimetric probes are attractive because they can be read with the naked eye, in some cases at the point of use, most of these probes are based on a fluorescent dye to achieve high sensitivity. Therefore, it is desirable to develop a colorimetric probe for $\mathrm{Pb}^{2+}$ with a sensitivity as high as a fluorescent probe.

Gold nanoparticles (AuNPs) are a good chromogenic dye for the development of a colorimetric sensing system because AuNPs have extinction coefficients, 3 - 5 orders of magnitude higher than those of organic dye molecules, and have unique distance-dependent optical properties that can be programmed chemically using specific host compounds that can induce a dramatic red-to-blue color change in AuNPs. ${ }^{4}$ Thus far, several AuNPs based-colorimetric sensing systems of $\mathrm{Pb}^{2+}$ have been developed using chemical functionalized AuNPs, ${ }^{5}$ a mixture of DNA functionalized AuNPs and DNAzyme, ${ }^{6}$ and $\mathrm{Pb}^{2+}$ catalyzed-leaching of AuNPs. ${ }^{7}$ Although colorimetric sensing methods based on DNAzyme and $\mathrm{Pb}^{2+}$ catalyzed-leaching of AuNPs are quite sensitive and selective, these methods are quite sensitive to conditions, such as $\mathrm{pH}$, temperature and composites of the reaction media, because these systems rely on catalytic reactions. ${ }^{6,7}$ A chemical functionalized AuNPs based system is free from these problems. However, 11-mercaptoundecanoic acid-functionalized based AuNPs system showed low selectivity and sensitivity. ${ }^{5 \mathrm{a}}$ In addition, glutathione functionalized AuNPs required additional salt to induce a color change in a AuNPs solution after adding $\mathrm{Pb}^{2+} \cdot 5 \mathrm{~b}$ Therefore, these systems have particular limitations.

Alkyl phosphates are potentially good ligands for $\mathrm{Pb}^{2+}$ because $\mathrm{Pb}^{2+}$ easily forms solids with phosphates, e.g. $\mathrm{Pb}\left(\mathrm{HPO}_{4}\right)$ and $\mathrm{Pb}_{3}\left(\mathrm{PO}_{4}\right)_{2}$ have solubility products of only $10^{-11.4} \mathrm{M}_{2}$ and $10^{-44.4} \mathrm{M}_{5}$, respectively, and approximately $95 \%$ of the body burden of lead is stored in the bones as lead phosphate derivatives. ${ }^{8}$ With this information, it is expected that alkyl phosphatefunctionalized AuNPs (Phos-AuNPs) can be used as a colorimetric probe for the detection of $\mathrm{Pb}^{2+}$ because alkyl phosphatefunctionalized AuNPs can interconnected with $\mathrm{Pb}^{2+}$ and induce a dramatic red-to-blue color change in the AuNPs as illustrated

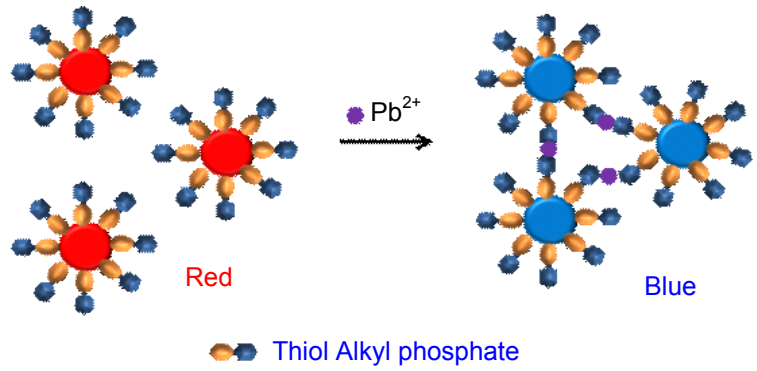

Scheme 1. Schematic representation of the $\mathrm{Pb}^{2+}$ chemosensor

in Scheme 1.

To evaluate the sensitivity of Phos-AuNPs for $\mathrm{Pb}^{2+}$, Figure 1a shows the absorbance changes in Phos-AuNPs in the presence of various concentrations of $\mathrm{Pb}^{2+}$. The addition of $\mathrm{Pb}^{2+}$ induced a decrease in absorbance at $520 \mathrm{~nm}$, and as shown in Figure 1b, the observed absorbance intensity was almost proportional to the $\mathrm{Pb}^{2+}$ concentration. The absorbance changes are a wellknown phenomenon that is used to confirm the formation of nanoparticle aggregates ${ }^{5}$ and the aggregation of Phos-AuNPs was identified by transmission electron microscopy (Figure 1c). Therefore, Phos-AuNPs were aggregated by $\mathrm{Pb}^{2+}$, which caused a dramatic red-to-blue color change as illustrated in Scheme 1. The detection limit of Phos-AuNPs for $\mathrm{Pb}^{2+}$ was estimated to be $1.637 \mu \mathrm{M}$ from the titration results and was as low as fluorescent probes. Also, we studied the effect of the $\mathrm{pH}$ value of the medium on $\mathrm{Pb}^{2+}$ sensing of Phos-AuNPs in the $\mathrm{pH}$ range of 4 - 9 because phosphate derivatives are generally sensitive to $\mathrm{pH}$. The Phos-AuNPs aggregated immediately in $\mathrm{pH} 4$ and was not sensitive to $\mathrm{Pb}^{2+}$ in $\mathrm{pH} 5$ and 9. However, Phos-AuNPs are stable in the $\mathrm{pH}$ range of $6-8$ and $\mathrm{Pb}^{2+}$ can lead to a strong response in the $\mathrm{pH}$ range (see supporting information). In addition, this method was more sensitive than the alkyl carboxylic acid modified AuNPs-based method, ${ }^{5 a}$ and did not require an additional salt to induce dramatic color changes in the AuNP solution, unlike the cysteine modified AuNPs-based method. ${ }^{5 \mathrm{~b}}$

Another important property of this method is its selectivity for $\mathrm{Pb}^{2+}$ over other metal ions. The selectivity of Phos-AuNPs for various metal ions was evaluated and the absorbance changes in the Phos-AuNPs in the presence of other metal ions were measured. Figure 2 shows the absorbance spectra of the solutions of Phos-AuNPs recorded after adding each metal ion. As shown in Figure 2, $\mathrm{Zn}^{2+}$ also induced a slight color change in Phos-AuNPs but no significant changes in the absorbance were observed upon the addition of other metal ions. This selectivity 
(a)

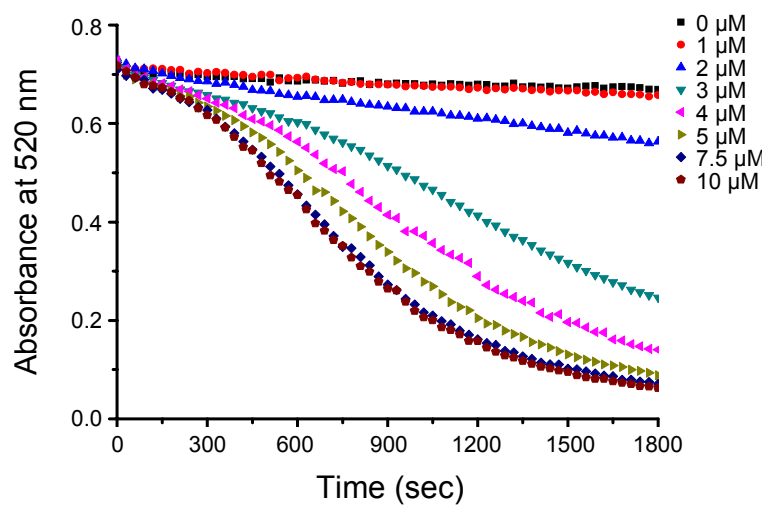

(c)

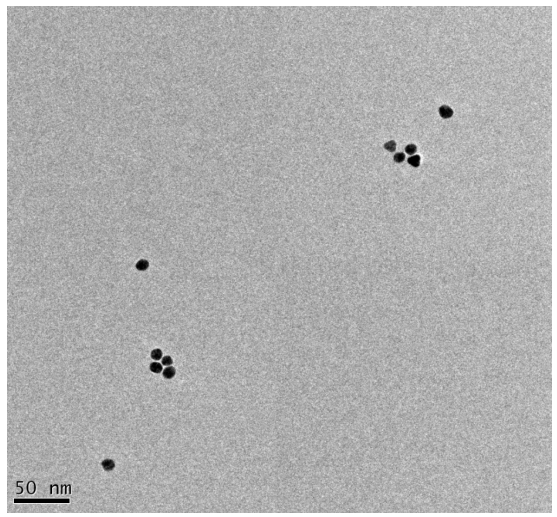

(b)
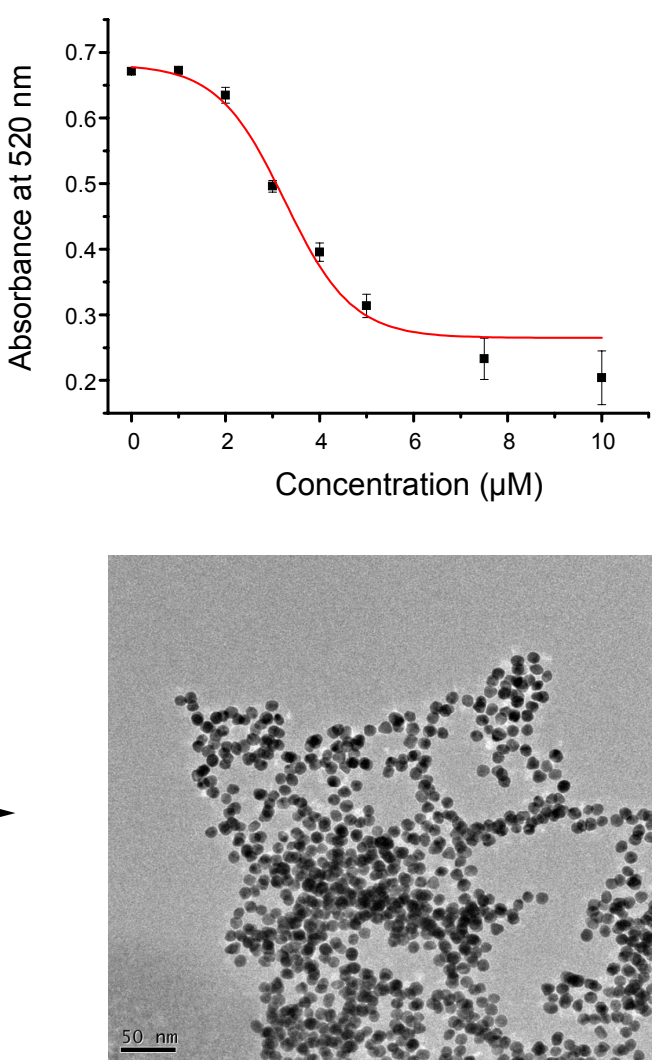

Figure 1. (a) Absorbance changes in $\mathrm{pH} 7.0$ buffer solutions (10 mM HEPES) containing Phos-AuNPs ( $3 \mathrm{nM})$ in the presence of various concentrations of $\mathrm{Pb}^{2+}$. (b) Plot of the assay solution absorbance intensities at $520 \mathrm{~nm}$ versus $\mathrm{Pb}^{2+}$ concentration. (c) TEM images of Phos-AuNPs in the absence of $\mathrm{Pb}^{2+}$ and presence of $\mathrm{Pb}^{2+}$ at $\mathrm{pH}$ 7. Scale bar represents $50 \mathrm{~nm}$.

(a)

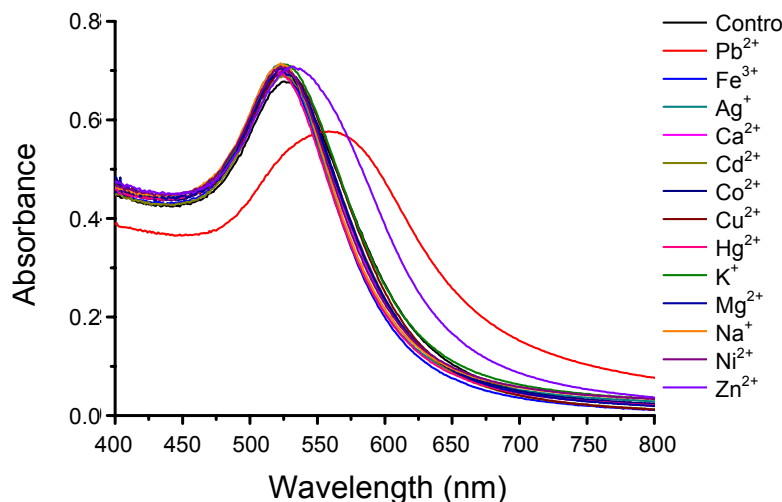

(b)

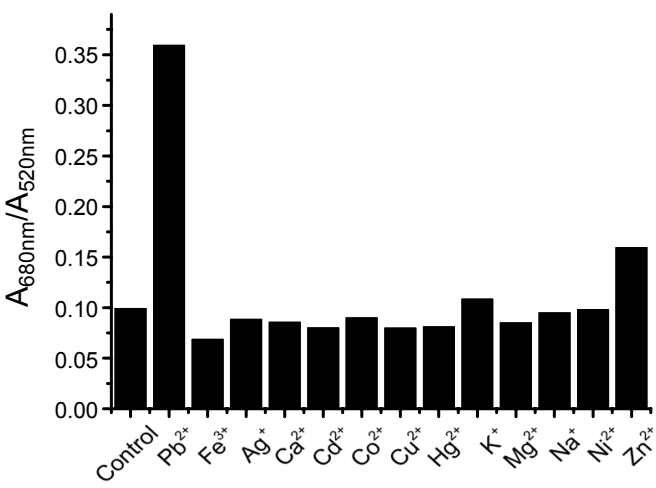

(c)

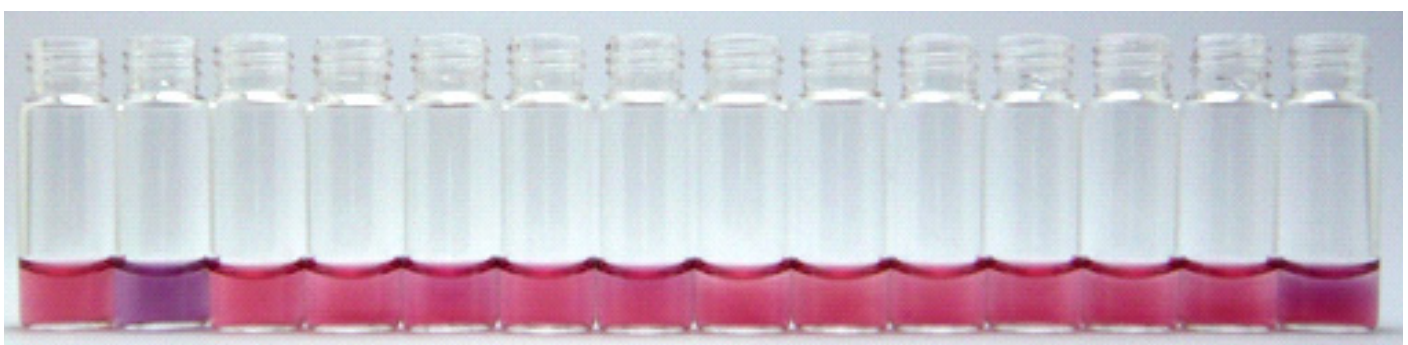

Figure 2. (a) UV-vis spectra obtained by adding various metal ions $(3 \mu \mathrm{M})$ in $\mathrm{pH} 7.0$ buffer solution (10 mM HEPES) containing Phos-AuNPs $(3 \mathrm{nM})$. (b) Plot of the absorbance ratios of the assay solutions versus various metal ions. (c) The color of the solution in the presence of various metal ions $(3 \mu \mathrm{M})$ : from left to right; control, $\mathrm{Pb}^{2+}, \mathrm{Ag}^{+}, \mathrm{Ca}^{2+}, \mathrm{Cd}^{2+}, \mathrm{Co}^{2+}, \mathrm{Cu}^{2+}, \mathrm{Fe}^{3+}, \mathrm{Hg}^{2+}, \mathrm{K}^{+}, \mathrm{Mg}^{2+}, \mathrm{Na}^{+}, \mathrm{Ni}^{2+}, \mathrm{Zn}^{2+}$. 
(a)

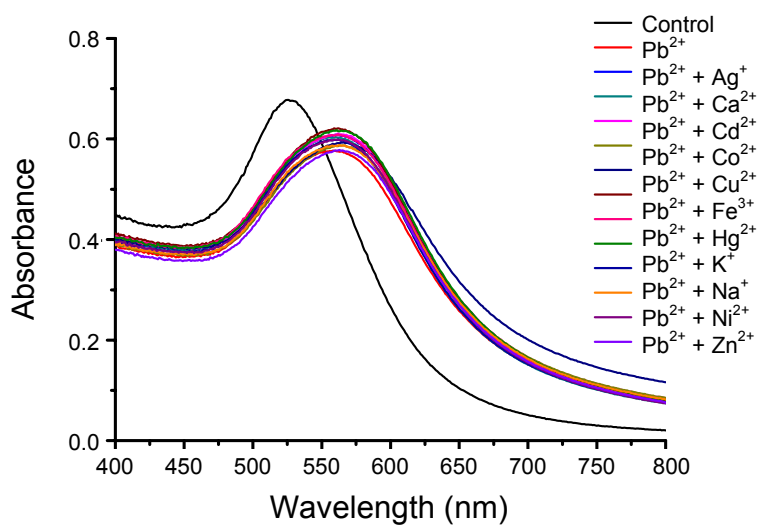

(b)

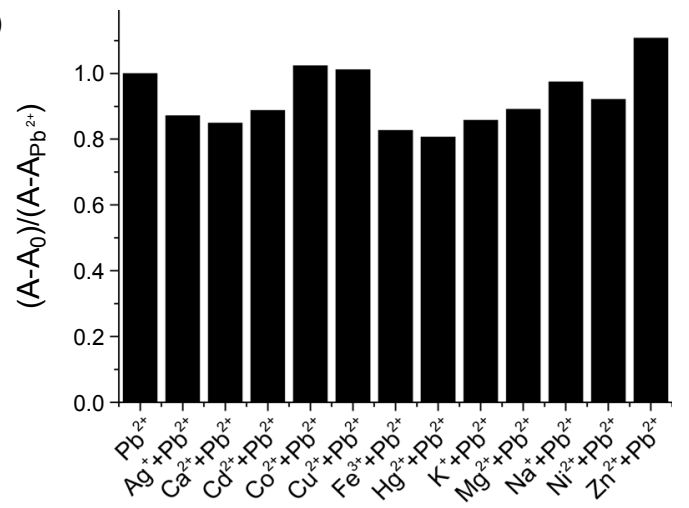

Figure 3. (a) UV-vis spectra obtained by the addition of $\mathrm{Pb}^{2+}(3 \mu \mathrm{M})$ with other metal ions $(3 \mu \mathrm{M})$ to the buffer solution containing sAuNPs (3 nM). (b) Plot of the absorbance intensity of the assay solution versus $\mathrm{Pb}^{2+}(3 \mu \mathrm{M})$ and other metal ions $(3 \mu \mathrm{M})$ at $520 \mathrm{~nm}$.

might be due to the fact that the ionic radius of $\mathrm{Pb}^{2+}$ is larger than that of other metal ions because the large ionic radius of $\mathrm{Pb}^{2+}$ may provide multivalent sites for phosphate ligands on AuNPs. ${ }^{9}$ In addition, sensors that can detect analytes by the naked eye are attractive because of their convenience. The use of this method for such a purpose is demonstrated in Figure 2C. Although the red to blue color change occurred when $\mathrm{Zn}^{2+}$ were added to an aqueous solution of Phos-AuNPs, $\mathrm{Pb}^{2+}$ caused a more dramatic color change than $\mathrm{Zn}^{2+}$.

The presence of background metal ions can interfere with the selectivity of the developed probe. To eliminate the possibility, the $\mathrm{Pb}^{2+}$-induced absorbance changes in the Phos-AuNPs were measured in the presence of these metal ions. The UV-vis spectra of the Phos-AuNPs solutions were recorded $15 \mathrm{~min}$ after adding $\mathrm{Pb}^{2+}(3 \mu \mathrm{M})$ and a possible interfering metal ion $(3 \mu \mathrm{M})$. As shown in Figure 3, no other metal ions affected the selectivity of the Phos-AuNPs for $\mathrm{Pb}^{2+}$.

In conclusion, Phos-AuNPs is an effective colorimetric probe for $\mathrm{Pb}^{2+}$. The proposed Probe can detect $\mathrm{Pb}^{2+}$, both spectrophotometrically and visually, in aqueous solutions at physiological $\mathrm{pH}$ with high selectivity toward $\mathrm{Pb}^{2+}$ over a variety of metal ions. Moreover, the selectivity is retained even in the presence of other metal ions. In addition, this AuNP-based method has a low detection limit as low as fluorescent chemosensor.

\section{Experimental Section}

Chemicals. All chemicals used were of analytical grade or of the highest purity available. Chloroauric acid $\left(\mathrm{HAuCl}_{4} \cdot 3 \mathrm{H}_{2} \mathrm{O}\right)$, citric acid and metal salts were purchased from Sigma Aldrich (USA). All glassware was cleaned thoroughly with freshly prepared aqua regia $\left(3: 1(\mathrm{v} / \mathrm{v}) \mathrm{HCl} / \mathrm{HNO}_{3}\right)$ and rinsed thoroughly with Milli-Q water prior to use. Milli-Q water was used to prepare all the solutions in this study.

Preparation of Phos-AuNPs. All glassware was washed with freshly prepared aqua regia $\left(3: 1=\mathrm{HCl}: \mathrm{HNO}_{3}\right)$ followed by extensive rinsing with doubly distilled $\mathrm{H}_{2} \mathrm{O}$. Citric acid stabilized Au particles with a diameter of $13 \mathrm{~nm}$ were prepared by adding $50 \mathrm{~mL}$ of a citrate solution $(38.8 \mathrm{mM})$ to $500 \mathrm{~mL}$ of boiling $1.0 \mathrm{mM} \mathrm{HAuCl}_{4} \cdot 3 \mathrm{H}_{2} \mathrm{O}$ with vigorous stirring. After the appearance of a deep red color, boiling and stirring were continued for $15 \mathrm{~min}$. The solution was then allowed to cool to room temperature with continued stirring. 1\% TWEEN 20 solution $(1.5 \mathrm{~mL}$ ) was added to the $30 \mathrm{~mL}$ of the citric acid stabilized $\operatorname{AuNPs}(11.5 \mathrm{nM})$ and $12 \mathrm{~mL}$ of 11-mercaptoundecyl phospholic acid $(10 \mathrm{mM})$ in THF was added to the solution 5 times in 36 hours at the same intervals. The solution was adjusted with a $1 \mathrm{mM}$ HEPES buffer ( $\mathrm{pH} 7.0$ ) using $30 \mathrm{mM}$ HEPES buffer and incubated for 12 hours. After incubation, the un-reacted 11-mercaptoundecyl phospholic acid and TWEEN 20 were eliminated by centrifuging 2 times and the Phos-AuNPs were kept in distilled water.

Colorimetric assay for $\mathrm{Pb}^{2+}$. Solutions of Phos-AuNPs ( $\left.3 \mathrm{nM}\right)$ in HEPES buffer were mixed with various concentrations of $\mathrm{Pb}^{2+}$ and the UV/Vis spectra of the solutions were recorded after incubation for 15 minutes.

Acknowledgments. This research was supported by the Chung-Ang University Research Grants in 2010.

\section{References}

1. Rifai, N.; Cohen, G.; Wolf, M.; Cohen, L.; Faser, C.; Savory, J.; DePalma, L. Ther. Drug Monit. 1993, 15, 71.

2. Winder, C.; Carmichael, N. G.; Lewis, P. D. Trends Neurosci. 1982, 5, 207.

3. (a) Chen, C.-T.; Huang, W.-P. J. Am. Chem. Soc. 2002, 124, 6246. (b) Buie, N. M.; Talanov, V. S.; Butcher, R. J.; Talanova, G. G. Inorg. Chem. 2008, 47, 3549. (c) He, Q.; Miller, E. W.; Wong, A. P.; Chang, C. J. J. Am. Chem. Soc. 2006, 128, 9316. (d) Kwon, J. Y.; Jang, Y. J.; Lee, Y. J.; Kim, K. M.; Seo, M. S.; Nam, W.; Yoon, J. J. Am. Chem. Soc. 2005, 127, 10107. (e) Zapata, F.; Caballero, A.; Espinosa, A.; Tárraga, A.; Molina, P. J. Org. Chem. 2009, 74, 4787. (f) Kim, J. S.; Kim, H. J.; Kim, H. M.; Kim, S. H.; Lee, J. W.; Kim, S. K.; Cho, B. R. J. Org. Chem. 2006, 71, 8016. (g) Chang, K.-C.; Su, I.-H.; Senthilvelan, A.; Chung, W.-S. Org. Lett. 2007, 9, 3363. (h) Wu, J.-S.; Hwang, I.-C.; Kim, K. S.; Kim, J. S. Org. Lett. 2007, 9, 907.

4. (a) Rosi, N. L.; Mirkin, C. A. Chem. Rev. 2005, 105, 1547. (b) Lu, Y.; Liu, J. Acc. Chem. Res. 2007, 40, 315. (c) Stewart, M. E.; Anderton, C. R.; Thompson, L. B.; Maria, J.; Gray, S. K.; Rogers, J. A.; Nuzzo, R. G. Chem. Rev. 2008, 108, 494. (d) Ghosh, S. K.; Pal, T. Chem. Rev. 2007, 107, 4797. (e) Burda, C.; Chen, X.; Narayanan, R.; El-Sayed, M. A. Chem. Rev. 2005, 105, 1025.

5. (a) Kim, Y.; Johnson, R. C.; Hupp, J. T. Nano Lett. 2001, 1, 165. (b) Chai, F.; Wang, C.; Wang, T.; Li, L.; Su, Z. ACS Appl. Mater. Interfaces 2010, $2,1466$.

6. Liu, J.; Lu, Y. J. Am. Chem. Soc. 2004, 126, 12298.

7. Chen, Y.-Y.; Chang, H.-T.; Shiang, Y.-C.; Hung, Y.-L.; Chiang, C.-K.; Huang, C.-C. Anal. Chem. 2009, 81, 9433.

8. Da Costa, C. P.; Sigel, H. J. Biol. Inorg. Chem. 1999, 4, 508.

9. Saxena, S.; D’Souza, S. F. Environ. Int. 2006, 32, 199. 